\title{
Correction to: ST-segment changes during tilt table testing for postural tachycardia syndrome: correlation with exercise stress test results
}

\author{
Ramya Vajapey ${ }^{1}$ - Erika Hutt Centeno ${ }^{1} \cdot$ Erik H. Van Iterson ${ }^{1} \cdot$ Haitham M. Ahmed ${ }^{1} \cdot$ Kenneth A. Mayuga $^{1}$ (I)
}

Published online: 6 September 2019

(c) Springer-Verlag GmbH Germany, part of Springer Nature 2019

Correction to: Clinical Autonomic Research

https://doi.org/10.1007/s10286-019-00633-9

Unfortunately, the 3rd author name was incorrectly published in the original publication. The complete correct name is given below.

Erik H. Van Iterson

The original article has been updated.

The original article can be found online at https://doi.org/10.1007/ s10286-019-00633-9.

Kenneth A. Mayuga

kenneth.mayuga@alum.northwestern.edu

1 Department of Cardiovascular Medicine, Section of Cardiac

Electrophysiology and Pacing, Cleveland Clinic, 9500

Euclid Avenue, J2-2, Cleveland, OH 44195, USA 